\title{
Anagallis arvensis L. als Indikator der Anwesenheit von Viren aus der Gruppe der Samenlosigkeit (Akarpie) - Stolbur und Vergilbungskrankheiten
}

\author{
Ctibor Blatteŕ \\ Phytopathologische Abteilung des Biologischen Institutes der Tschechoslowakischen Akadefmie \\ der Wissenschaften, Praha
}

Souhrn

\begin{abstract}
Žloutenkové onemocnění Anagallis arvensis L. indikuje podle pozorování v přírodè př́tomnost virů ze skupiny akarpií (žloutenek a stolburu). Anagallis arvensis L. a Stellaria media (L.) VILL. indikovaly v pokusech v r. 1957 prítomnost těchto chorob, též purple-topu a yellow-topu u bramborủ, jestliže byli prítomni kř́sové Macrosteles laevis RIB. a Calligypona pellucida F. Pokus na stř̌ešní terase - při absenci obou jmenovaných druhů kř́sủ - ukázal, že uvedené choroby nebyly přeneseny křískem Empoasca favessens F., mšicemi různých druhủ, molicí Trialeurodes vaporariorum WESTw. V roce 1958 , kdy výskyt kř́sků byl slabší a pozdnějši, indikovaly uvedené rostliny - a Anagallis linitolia L. - rovněž prítomnost téchto virů $\mathrm{v}$ bramborových porostech (purple-top a yellow-top i $\mathrm{v}$ podhúrúi) nebo $\mathrm{v}$ jiných reservoirových rostlinách nebo $\mathrm{v}$ kříscích, ale slabẻji a později než v r. 1957. Anagallis arvensis L. a A. linifolia L. na některých místech indikuji přesněji skupinu aster yellow (evropskou žloutenku aster), pseudoklasický stolbur, purple-top a yellow -top bramborủ, na jiných skupinu klasického stolburu; př́ćiny toho nejsou známy. Žloutenka, přenesena křísky z Anagallis arvensis L. na rajčata, se u nich projevila jako pseudoklasický stolbur; yellow-top bramborů, žloutenky a klasický stolbur, přeneseny křísky na Anagallis arvensis L., projevily se u nich typickým zakrsáním květních korun. Silné kolísání výskytu těehto viros $\mathrm{v}$ př́rod (po $\mathrm{r}$. $1957 \mathrm{~s}$ velmi silným výskytem žloutenek ve středočeských polohách následoval rok $\mathrm{s}$ jejich velmi slabým výskytem) jo závislé na iniciálním vlivu vysokých teplot i na jiných př́činách, jako je kolísání hladiny virủ v hostitelských rostlinách. Anagallis arvensis L., Anagallis linifolia L., Stellaria media (L.) VILL. možno použít jako indikátorủ př́tomnosti virủ ze skupiny akarpií na určitém stanovišti. Pozorování o složení, časnosti a síle výskytu cikadofauny může sloužit $\mathrm{k}$ signalisaci zákrokủ pro nepř́mý boj proti těmto virosám.
\end{abstract}

\section{Zusammenfassung}

Die gelbsuchtartige Erkrankung von Anagallis arvensis L. zeigt nach Beobachtungen in der Natur die Gegenwart von Viren aus der Gruppe der Akarpien (Vergilbungen) und Stolbur an. Anagallis arvensis L. und Stellaria media (L.) 
VILL. zeigten bei Versuchen des Jahres 1957 die Anwesenheit dieser Krankheiten, sowie auch von purple-top und yellow-top der Kartoffeln an, sofern die Zwergzikaden Macrosteles laevis Rm. und Calligypona pellucida F. anwesend waren. Ein Versuch auf der Dachterrasse - in Abwesenheit beider genannten Zikadenarten - erwies, dass die angeführten Krankheiten weder von der Zwergzikade Empoasca flavescens F., noch von verschiedenen Blattlaus-Arten oder von Trialeurodes vaporariorum WESTW. übertragen wurden. Im Jahre 1958, da das Vorkommen der Zikaden schwächer und verspätet war, indizierten die angeführten Pflanzen - und Anagallis linifolia L. gleichfalls — die Anwesenheit dieser Viren in den Kartoffelbeständen (purple-top und yellow-top selbst im Vorbergland), oder auch an anderen ReservoirPflanzen, oder in den Zikaden, aber schwächer und später, als im Jahre 1957. Anagallis arvensis $\mathrm{L}$. und $A$. linifolia $\mathrm{L}$. indizieren an manchen Standorten genauer die Gruppe der aster-yellows (der europäischen Vergilbungskrankeit der Astern), den pseudoklassischen Stolbur, purple-top und yellow-top der Kartoffeln, an anderen Orten die Gruppe des klassischen Stolbur; die Ursachen davon sind nicht bekanint. Vergilbungskrankheit, durch Zikaden von Anagallis arvensis L. auf Tomaten übertragen, äusserte sich an ihnen als pseudoklassischer Stolbur; yellow-top der Kartoffeln, Vergilbungskrankheiten und der klassische Stolbur, durch Zikaden auf Anagallis arvensis L. übertragen, äusserten sich an dieser als typische Reduktion der Blütenkronen. Das starke Schwanken im Auftreten dieser Virosen in der Natur (nach dem Jahre 1957 mit sehr starkem Auftreten der Vergilbungen in den mittelböhmischen Lagen folgte ein Jahr sehr geringen Vorkommens) ist abhängig von der Initialquelle der Ansteckung, dem Beginne des Auftretens und der Vermehrung der Zikaden, sowie auch vom inaktivierenden Einfluss hoher Temperaturen und auch von anderen Gründen, wie beispielsweise vom Schwanken des Virenspiegels in den Wirtspflanzen. Anagallis arvensis L., Anagallis linifolia L., Stellaria media (L.) VILL. kann man an einem bestimmten Standort als Indikatoren der Anwesenheit von Viren aus der Gruppe der Akarpien verwenden. Beobachtungen über Zusammensetzung, Termin und Stärke des Vorkommens der Zikadofaune können zur Signalisierung der Eingriffe für einen indirekten Kampf gegen diese Virosen dienen.

\section{Einleitung}

Ưber die Virosen, welche Blütenanomalien beim Ackergauchheil (Anagallis arvensis L.) im weiteren $A$. $a$. bezeichnet) hervorruft, siehe BLATTNÝ (1957). Im Jahre 1957 und 1958 haben wir mit dieser Pflanze weiter experimentiert. Kranke A. a. sowie Stellaria media (L.) VILL. und auch Ehrenpreisarten, vornehmlich Veronica chamaedrys L. oder einige von diesen Arten treten regelmässig dort auf, wo sich andere Pflanzenarten, insbesondere Kulturpflanzenarten befinden, die von Stolbur oder Vergilbungskrankheiten befallen sind. Wir nahmen darum Versuche vor, um festzustellen, ob nicht $A$. $a$. als Indikator dieser Virosen verwendet werden könnte. Eine vorläufige Mitteilung über diese Arbeiten siehe BLattrí (1958a, b). 
Dazu gesellte sich auch ein Versuch, der mit den vorhergehenden zusammenhing: Ob und zu welchem Anteil $A$. $a$. mit Viren aus der Gruppe der Akarpien von Kartoffeln infiziert werden kann und ob sich die Erkrankung von $A$. $a$. unter Terrainbedingungen auf Tomaten übertragen lässt.

\section{Teil. Jahr 1957}

Třebotovice bei Ceské Budæ̌jovice. Die Versuche wurden auf einem ebenen, mit Gras bewachsenen Grundstück am 24. Mai angelegt und die Grösse der Versuchsparzelle betrug $3 \times 3 \mathrm{~m}$.

Versueh Nr. 1. Es wurden zehn gesunde Tomatenpflanzen gesetzt und zwischen sie (24. V. 1957 - gilt auch für die weiteren Versuche) 20 viröse $A$. a., die im Glashaus gezüchtet und infiziert worden sind. Auf dieser Parzelle wuchsen auch noch 5 gesunde A. a.-Pflanzen aus Samen. Im Verlaufe der Vegetation zeigten in der Hälfte des Juni drei Tomatenstauden kleinere, anthokyanisierte Hochblätter und ,gotischen" Wuchs. In der späteren Phase, Anfang August, hatten zwei dieser Tomatenpflanzen verkümmerte Blütenkronen. Die kranken $A$. $a$. verzweigten sich intensiv und blühten nicht. In einer Entfernung von $12 \mathrm{~m}$ von dieser Parzelle befand sich ein Kartoffelbestand der Sorte ,Erstling“, Ende April ausgesetzt.

Versuch Nr. 2. Es wurden zehn gesunde Tomatenpflanzen und zwanzig gesunde A. a.-Exemplare ausgesetzt. Diese Versuchsparzelle war 28 Meter von der vorhergenannten Parzelle entfernt und $40 \mathrm{~m}$ von den nächstwachsenden Kartoffelstauden. Bis zu Ende des Velsuches blieben alle Pflanzen gesund - wurde nicht virös.

Versuch Nr. 3. Auf einer Parzelle, die von den allernächsten Kartoffelpflanzen der Sorten "Ackersegen" und ,Triumf" $80 \mathrm{~m}$ entfernt lag, wurden zehn Kartoffelknollen mit Fadenkeimen ausgesetzt, die von Baři bei Košice stammten, wo im Vorjahre der Kartoffelbestand stark von Stolbur befallen war. In der Hälfte des Juni gaben zwei Kartoffelpflanzen mässige Anzeichen von yellow-top zu erkennen und eine Kartoffelstaude Kennzeichen, die ,,kudrjašce genannt werden. Anfang August wiesen vier Kartoffelpflanzen mässige Anzeichen von yellow-top auf und dieser Stand blieb bis zur Ernte Ende September unverändert, bei welcher unter 26 Knollen, die geerntet wurden, zwei spindelförmig waren. Von diesen Knollen zeigten im Frühjahre des nächsten Jahres 22 Knollen normale Keimtriebe und vier Knollen hatten halbfadenförmige Keimtriebe.

Von den ausgesetzten $A$. $a$. hatten in der Junihälfte drei Pflanzen ziegelrote Blüten, die oberen Blüten hatten kleinere Kronen und zusammengedrängte Hochblätter. Anfang August. wiesen bereits 8 Pflanzen typische Erkrankungsmerkmale auf (starke Reduktionen der Blütenkronen in den Gipfelpartien), was bis zum Ende der Vegetation so blieb. Ende September zeigten bei der Ernte der Kartoffeln bereits alle 20 ausgesetzten $A$. a.-Exemplare typische Erkrankungsmerkmale der Gipfelpartien. Auch von 22 Sämlingen der Art Stellaria media (L. VILL. zeigten drei Pflanzen und von 18 Sämlingen von Veronica chamaedrys L. 5 Pflanzen typische Vergilbungskrankheiten.

Versuch Nr. A. Auf einer Parzelle, die von den nächsten Kartoffelstauden der Sorten ,Ackersegen" und "Triumf" 80 Meter und von der Parzelle Nr. 335 Meter entfernt lag, wurden 10 Kartoffelknollen ausgesetzt, die in dieser Gemeinde geerntet worden sind, normale Keimtriebe hatten und auch von einem Grundstück stammten, auf welchem sich im Vorjahre während der Vegetation keine Stolbur-Erkrankung gezeigt hatte. Zwischen sie wurden 10 gesunde A. a.-Exemplare gesetzt. Bis zur Ernte blieben die Kartoffeln von diesen Knollen ohne Symptome von Virosen aus der Gruppe der Akarpien und von 10 gesunden A. a.-Pflanzen erkrankte nur eine Pflanze an Vergilbung.

Die Lokalität dieser Versuche ist von mittlerer Eignung für die Züchtung von Pflanzgutkartoffeln. Sorten, die gegen Virosen empfindlich sind, halten es hier ohne besondere Verbreitung dieser Virosen und ohne merkbares Absinken der Erträge $4-5$ Jahre aus. In der weiteren Umgebung dieser Lokalität wurden vereinzelte Exemplare von A. a. und Stellaria media (L.) VILL. festgestellt, die an einer Vergilbung des beschriebenen Typs erkrankt waren. In den Kartoffelbeständen der Umgebung wurden vereinzelte Purple-top- und yellow-top- 
Fälle festgestellt. Bei Hypericum perforatum L. wurde ein vereinzelter Fall von Vergilbung und bei Trifolium repens L. Phyllodie festgestellt. Die Population der Zwergzikaden war sehr zahlreich und es überwogen die Arten Macrosteles laevis RIB. und Calligypona pellucida F., welche die Infektionen von den kranken Versuchsexemplaren von A. a. und Kartoffeln in die Umgebung verschleppten, wie aus den Versuch Nr. 4. ersichtlich ist und aus einigen Fällen kranker Veronica chamaedrys-Exemplare in der Nähe der Versuchsparzellen 1 und 3 und aus erkrankten Kartoffelstauden der Sorte ,Erstling“, 12 Meter von der Versuchsparzelle Nr. 1 entfernt. Während der Vegetation äusserten diese Kartoffeln weder Anzeichen der Blattrollkrankheit, noch des pseudoklassischen Stolburs und wurden für Pflanzgutzwecke in der zweiten Augusthälfte geerntet. Proben der Knollen aus der Ernte wurden einer Vorkeimung unterzogen und von 304 Knollen zeigten zwei (d. i. 0,66\%) Fadenkeimtriebe. Es handelte sich um eine Ansteckung von kranken A. a.-Pflanzen auf der Versuchsparzelle Nr. 1. Niemals vordem - nach Beobachtungen vom Jahre 1924 an -- sind hier fadenförmige Keimtriebe beim Pflanzgut festgestellt worden. Dass es sich um eine Ansteckung im betreffenden Jahre handelte, wurde auch durch die Tatsache bestätigt, dass von den nach der Ernte als Unkraut auf dem Grundstück wachsenden Vogelmierenpflanzen [Stellaria media (L.) VILL.] 1,2\% der Pflanzen Anzeichen von Vergilbung zeigten. Es scheint, dass Zwergzikaden der Art C. pellucida F. diese Ansteckung in den sonnenwarmen Tagen des Oktobers übertrugen. Sie verschleppten diese auch auf die in der Nähe angebauten Narzissen, von denen zwei von 30 Pflanzen im nächsten Jahre grüne Blüten aufwiesen, obwohl an diesem Orte Narzissen schon 30 Jahre gezüchtet worden waren, ohne dass ein Grünwerden der Blüten festgestellt vorden wäre.

Die viröse Vergilbung wurde also von den kranken A. a.-Exemplaren auf Tomaten und von kranken Kartoffeln auf A. a., Stellaria media (L.) VILL., Veronica chamaedrys L. und auch wieder auf Kartoffeln übertragen. A. a. indizierte also die Anwesenheit der Vergilbungskrankheit der Gipfelpartien bei den Kartoffeln, unter we shen sie wuchs.

\section{Teil. Jahr 1957}

Versuchsort ist der Garten der phytopathologischen Abteilung des Biologischen Institutes der Tschechosl. Akad. d. Wiss. in Praha-Dejvice.

Versuch Nr. 5. Am 20. Mai wurden Knollendrittel einer Gesamtzahl von 400 Knollen ausgesetzt, die im Vorjahre in diesem Garten geerntet worden sind. Im Jahre 1956 befanden sich in diesem Bestand etwa $5 \%$ Pflanzen mit Anzeichen von purple-top, yellow-top und auch von ,Kudrjă̌̌ce“. Die im Bestand oder in seiner Nähe wachsenden Unkrautexemplare $A$. $a$. und Stellaria media (L.) VILL. zeigten Merkmale von Virosen, Plantago major L. Phyllodie der unter. sten Blüten der Blütenähre. Beim Vorkeimen der Knollen im Frühjahre 1957 wurden $0,2 \%$ mit Fadenkeimen festgestellt. Vor dem Lagern der Knollen im Herbst 1956 wurden 0,1\% weich. gewordene Knollen festgestellt. Im Jahre 1957 wurden schon Anfang Juli 0,2\% ,Kudrjašče* und bei 5,4\% purple-top und yellow-top festgestellt. Von 95 Unkrautexemplaren von $A$. $a$., die unter den Kartoffeln gewachsen waren, hatten 87 Blüten an den Gipfelpartien mit reduzierten Blütenkronen. Die in der Nachbarschaft der Kartoffeln unter der Zuckerrübe wachsenden $A$. a. waren noch völlig gesund, aber gegen Ende September wiesen doch zwei Pflanzen aus der Gesamtzahl von A. a. in der Zuckerrïbe Anzeichen viröser Vergilbung auf. Die in der Nähe in einem völlig geschlossenen Mistbeete wachsenden A. a.-Exemplare blieben bis zum Ende der Vegetation gesund. Am anderen Rande des Kartoffelfeldes wurden 20 Tomatenstauden ausgesetzt, von denen zu Ende der Saison 9, d. i. 45\%, Merkmale des pseudoklassischen Stolburs aufwiesen. Die in einem Teile desselben Gartens wachsenden A. a., die sich in einer Entfernung von 50-100 Meter befanden, abgetrennt durch Rasen und Wäldehen, blieben bis zum Ende der Vegetation gesund. Von Ende Juni an befanden sich im Garten und auf den Versuchsfeldern zahlreiche Zwergzikaden, vor allem Empoasca flavescens F., Macrosteles laevis RrB. und Calligypona pellucida $\mathrm{F}$.

Die Virusinfektion wurde also auf $A$. $a$. durch Zikaden von kranken Kartoffeln übertragen, die Symptome von purple-top, yellow-top und ,kudrjašč “ aufwiesen. Infektionsquelle waren Knollen aus der Ernte des Jahres 1956. Später übertrugen die Zikaden die Infektion auch auf die Tomaten und die Unkrautstauden A. a. der nüchsten Nachbarschaft, keineswegs aber an entferntere oder isolierte Orte.

Versuch Nr. 6. In den Kartoffelbestand des Versuches Nr. 5 wurden Anfang Juli, dann in der Hälfte und gegen Ende dieses Monats nacheinander je 25, 10 und 10 gesunde, im Glas- 
hause gezüchtete A. a.-Exemplare ausgesetzt. Von diesen 45 ausgesetzter $A$. a. zeigten im ganzen drei Pflanzen Anzeichen einer Vergilbungskrankheit und zwar zwei Pflanzen, die Ende Juli und eine, die Mitte dieses Monats ausgesetzt worden waren. Symptome waren samt und sonders pathologische Veränderungen der Blüten an den Stengelgipfelpartien.

Versuch Nr. 7. Es wurden im Glashause gleichfalls Drittel von Kartoffelknollen entsprechend dem Versuch Nr. 5 ausgesetzt und zwischen sie gesunde A. a. und Stellaria media (L.) VILI. Sie wuchsen in einem insektensicheren Glashause. Alle A. a. und auch Stellaria (L.) VILL. blieben gesund.

Versuch Nr. B. Auf der Dachterrasse des Biologischen Instituts der Tschechosl. Akad. d. Wissenschaften wurden die verbleibenden Drittel der 400 Kartoffelknollen ausgesetzt, die in Versuch Nr. 5 und 7 verwendet worden sind. Das ausgewachsene Kraut wies Kennzeichen von ,kudrjašče", purple-top und auch yellow-top zu gleichen Teilen wie bei Versuch 5 und 7 auf, aber wesentlich schwächer. Anfang Juni wurden hier Tomaten ausgesetzt, die mit Vergilbungsvirus mittels Pfropfreis von Ackerwinde (Convolvulus arvensis I.) Anagallis arvensis L. und Stellaria media (L.) VrLL. infiziert worden waren. An den Tomaten befanden sich zahlreiche Blattläuse und Trialeurodes vaporariorum Westw. Zwischen die Kartoffeln wurden am 9. Juli 10 und 18. Juli 20 gesunde $A$. a.-Exemplare ausgesetzt. Sowohl diese A. a., als auch die aus Samen aufgewachsenen $A . a$. blieben bis zum Vegetationsende gesund, was auch für Stellaria media (L.) VILL. und für Veronica chamaedrys L., die ebenfalls aus Sarnen aufgewachsen sind, gilt. Gegen Ende Juli wurde neben den bereits erwähnten Blattlänsen und Trialeurodes auch noch die Zikade Empoasca flavescens F. festgestellt. Von den Kartoffeln wurde die Erkrankung darum nicht übertragen, weil hier keine Zikaden vorhanden waren, welche Virosen aus der Gruppe des Stolbur übortragen und weil Blattläuse und Trialeurodes für diese Krankheiten keine Vektoren sind. A. a. kann darum nur dort ein Indikator von Virosen aus der Gruppe der Vergilbungskrankheiten und des Stolbur sein, wo sich auch ihre Überträger befinden.

\section{Teil}

Versueh Nr. 9. Versuchsstelle ist Dol bei Libčice, auf einer Jokalität, auf welcher schon vom Jahre 1954 an klassischer Stolbur festgestellt worden ist (,Dol-Starm") mit typischen Symptomen der Hypertrophie der Kelche bei den Tomaten (BLATTNÝ et al. 1956). Hier konnte man charakteristisch erkrankte Exemplare von Ackerwinde [Convolvulus arvensis L.,) A. a., Stellaria media (L.) ViLL., Veronica sp., Reseda sp. in je nach den Jahren schwankender Menge finden. Hier wurde ebenfalls der klassische Vektor des Stolburs, die Zikade Hyalesthes obsoletus SIGN. in einer Intensität festgestellt, die den einzelnen Jahren entsprach.

Im Jahre 1957 wurden hier die Anzeichen der europäischen aster-yellows bei einer ziemlich grossen Anzahl von Pflanzen festgestellt, beispielsweise bei ca 30\% Gaillardia amblyodon Gay, $5 \%$ Delphinium ajacis L., 20\% Antirrhinum majus L., 20\% Scabiosa atropurpurea DESE., $5-10 \%$ Callistephus chinensis (L.) Ness., 15\% Centaurea americana NuTT., 10\% Reseda odorata L., $10 \%$ Anchusa capensis ThuNG., 5\% Malope trifida Cav. grandiflora hort., $15 \%$ Eschscholtzia californica Снам., 100\% Blumenkohl, Convolvulus arvensis L., und A. a. mit schweren Kennzeichen der Virose. Bei Tulpen, Krokussen und Anemonen, die von anderer Stelle her versetzt worden sind, wurden keinerlei Krankheitszeichen festgestellt.

Im Jahre 1958 sank der Anteil an derartig erkrankten Pflanzen auf ein Minimum: Callistephus sp. 0,1\%, Gailardia sp. 0,3\%, Eschscholtzia sp. 0,6\%, Gypsophila elegans BIEB. 2,6\%, die übrigen ohne Anzeichen. Die Ackerwinden blieben hier auch weiter virös, der Anteil an erkrankten Pflanzen war um 50\% niedriger, als im Jahre 1957. A. a.-Exemplare, die zwischen den Ackerwinden wuchsen, erkrankten im Jahre 1958 an typischer, viröser Vergilbung, jedoch nur in 10\% der Anzahl des Jahres 1957.

Im Jahre 1954 zeigten Tomaten, die hier unter die kranken Ackerwinden gesetzt worden waren, zu 10\% die gleichen Anzeichen klassischen Stolburs (,Dol-Stamm“). Im Jahre 1958 wurden hier 100 Tomatenstauden gesetzt und von ihnen erkrankte 1\% unter Anzeichen des pseudoklassischen Stolburs (,Loděnicer Stamm“). Die Identität der Frkrankung, wie sie sich an den hier angeführten Zierpflanzen zeigte, mit dem klassischen Stolbur, ist bisher noch nicht erwiesen worden. Im Jahre 1957 gab es hier viele Zikaden Macrosteles laevis Ris. und Calligypona pellucida F., bei denen erwiesen worden ist, dass sie Uberträger der Viren dieser Gruppe sein können (Hernze et al. 1955, Blattný 1957, Musil und Valanta 1958). 
IV. Teil

Versuch Nr. 10. Versuchsort: Lodĕnice bei Beroun. Auf einer Lokalität, auf der sich Convolvulus arvensis mit Anzeichen von Stolbur befand, wurden im Jahre 195420 Tomatenstauden ausgesetzt, von denen $10 \%$ Symptome des pseudoklassisehen Stolburs zeigten (,,Loděnicer Stamm“, BLAttrý et al., 1956). In den Jahren 1956 und 1957 wuchsen ständig auf dieser Lokalität kranke Exemplare von Convolvulus arvensis L., A. a. und zwar sowohl die blaue wie die rote Form sowie (weniger) erkrankte Stellaria media (L.) VILL. und Veronica sp. In der Zikadenpopulation, die vom Jahre 1954 an verfolgt wurde, herrschten Macrosteles laevis RIB. und Calligypona pellucida F. vor. Hyalesthes obsoletus SrGN. wurde hier trotz zahlreicher Versuche, diese Art zu fangen, bisher nicht gefunden.

In der Hälfte Mai 1958 wurden hier zwischen die kranken Convolvulus-Exemplare 100 Tomaten ausgesetzt. Anfang September wurden bei 1\% Tomaten Symptome des pseudoklassischen Stolburs mit nahezu samenlosen Früchten festgestellt. Die Zahl der Zikaden dieses Jahres sank auf ein Zehntel des Standes vom Jahre 1957 und das Vorkommen war gleichfalls um drei Wochen verspätet. Auch die Zahl der kranken Exemplare von Convolvulus arvensis L. und $A$. a. sank um ein Drittel. resp. vier Fünftel.

\section{Teil}

Versueh Nr. 11. Versuchsstelle: Garten der phytopathologischen Abteilung des Biol. Inst. der Tschechosl. Ak. d. Wiss., Praha-Dejvice. Auf dem Felde wurden Kartoffelknollen mit Fadenkeimen ausgesetzt. Während der Vegetation zeigten $2,9 \%$ von ihnen Symptome von purple-top und yellow-top. In der Nachbarschaft befand sich ein Maisbestand und in demselben wuchsen aus Knollen, die im Boden überwintert waren, auch Kartoffeln. In beide Kartoffelbestände wurden am 5. und 11. Juni im ganzen 50 gesunde $A$. a.-Exemplare ausgesetzt und weitere 16 wuchsen dort aus Samen auf. Bis zum Ende der Vegetation äusserte sich nur bei zwei Exemplaren von $A$. a. eine viröse Erkrankung und zwar in Form zerfranster und reduzierter Kronen der Gipfelblüten. Gegenüber dem Jahre 1957 war der Prozentanteil der erkrankten Pflanzen weit niedriger, obwohl die Zusammensetzung der Zikadofanna die gleiche geblieben ist. Nur $2 \%$ der Tomatenpflanzen, die in nächster Nachbarschaft wuchsen, erkrankten an pseudoklassischem Stolbur zum Unterschied von 45\% des Jahres 1957.

Versuch Nr. 12. Versuchstelle: Kartoffelzüchtungsstation Keřkov, $540 \mathrm{~m}$ über dem Meeres. spiegel. Zwischen den Kartoffelbestand wurden 85 gesunde Exemplare A. a. und 15 A. linifolia L. (A. grandiflora hort.) ausgesetzt. Ende August wiesen 59 Exemplare A. a. und alle $A$. linifolia L. Symptome der typischen Virose auf - Fransigkeit und später völlige Reduktion der Blütenkronen. Ende Juli wurden hier weitere 25 A. linifolia L. ausgesetzt, die bis Ende August noch nicht blühten und bereits deformierte Gipfelblätter aufwiesen. Durch die Kartoffelernte wurden diese Pflanzen vernichtet. Von Zikaden waren in den Pflanzenbeständen besonders folgende Arten anwesend: Empoasca flavescens F., M. laevis RIB., und C. pellucida F., schwächer Euscelis plebejus FALL. sowie Aphrodes bicinctus Schrк. Anagallis linitolia L. erwies sich hier als Indikator der Anwesenheit von Viren aus der Gruppe der Vergilbungskrankheiten und des Stolburs genau so empfindlich, wie A. a. Auf die Empfindlichkeit dieser Art gegen den Komplex der Vergilbungskrankheiten machte mich Ing. C. BLATrNý jun. aufmeksam, der diese Art im Jahre 1957 im Libochovicer Gebiete stark an dieser Virose erkrankt vorfand. Im Kartoffelbestand in Ker̆kov zeigte etwa 1\% Pflanzen Ende Juni die Symptome von purple-top und yellow-top, die offensichtlich an $A$. a. und auch $A$. linifolia L. indiziert worden sind. In weiterer Umgebung des Versuchsfeldes trat Phyllodie bei Trifolium repens $\mathbf{L}$. und T. pratense $\mathbf{L}$. auf, deren Verhältnis zu purple-top und yellow-top nicht näher bestimmt, aber sicher sehr eng ist, wie die Arbeiten von WEB und SHULTZ (1955) an einer anderen Kleeart in der Beziehung der amerikanischen Vergilbungskrankheit der Astern zum purple-top bei Kartoffeln andeuten. Auf den Unterschied der Virus-Arten oder Stämme, die bei uns an Klee Phyllodie hervorrufen, vom Virus des Stolburs weist VALENTA (1958) hin.

Versuch Nr. 13. Versuchslokalität: Kartoffelfeld, 4 Hektar, Sorte „Krasava“, im Kataster Mikulov in Mähren. Ein typisches Vorkommensgebiet des klassischen Stolbur an allen Solanaceen, vor allem Kartoffeln, Tomaten, Paprika und Tabak in den Jahren 1952-56. Das Kartoffelpflanzgut stammte aus dem Böhmisch-Mährischen Hügelland. In der Zeit der Vege- 
tation sind in diesem Bestande weder Symptome von Stolbur, noch von purple-top oder yellowtop festgestellt worden. Vergilbungsartige Erkrankungen des Typs aster-yellows an Cirsium arvense Scop. und Carduus acanthoides $\mathrm{I}$., sowie an anderen Pflanzen fanden wir dort nur selten, aber A. a., sowohl die rotblütige, als auch die blaublütige Form, war dort in den vorhergehenden Jahren typisch virös. Im J. 1958 wurde in der Umgebung weder Stolbur noch Vergilbung festgestellt.

In den Kartoffelbestand wurden Ende Mai an verschiedenen Stellen 120 gesunde $A$. $a$. und 15 gesunde $A$. linifolia L. ausgesetzt. In der Julihälfte wurden weitere 78 Exemplare $A$. $a$. ergänzend gesetzt. Infolge der Trockenheit und anderer ungünstiger Bedingungen gingen 99 der ausgesetzten $A$. a.-Pflänzchen und alle $A$. linifolia L. zugrunde. Von den restlichen 99 A. a. äusserte Ende August nur eine einzige Pflanze viröse Symptome, blassere und kleinere Blütenkronen, mässig gewellte oberste Gipfelblätter und das Rosigwerden der Blattränder der Grundblätter. Es handelt sich ohne Zweifel um eine Infektion, die von Zikaden von irgendeiner an irgendeinem Virus der Gruppe der Akarpien erkrankten Pflanze der Umgebung iubertragen worden ist. Von Zikaden trat auf dieser Lokalität in den vergangenen Jahren sehr zahlreich Hyalesthes obsoletus SIGN. auf. Im Jahre 1958 wurden hier bloss Calligypona pellucida F., Macrosteles laevis RiB. und Euscelis plebejus FALL. festgestellt.

\section{Diskussion}

Wie im Jahre 1957, so indizierte $A$. $a$. auch im Jahre 1958 (das für Virosen dieser Art ungünstig war) die Anwesenheit von Viren dieser Gruppe in einer bestimmten Lage nach den bisherigen Versuchen exakter die Anwesenheit von Stämmen des sog. pseudoklassischen Stolbur (einschliesslich der europäischen aster yellows, purple-top und yellow-top an Kartoffeln) als die Anwesenheit des klassischen Stolbur. Aber auch dort, wo der klassische Stolbur häufig vorkommt, ist in der Regel auch die Virose von $A$. a. häufig; und Stolbur lässt sich durch die Zikade Euscelis plebejus Fall. auf $A$. a. übertragen und an ihr ruft er die typischen Kennzeichen der von uns beschriebenen Virose hervor. (VALENTa, MusIL 1958). Die Sachlage ist wahrscheinlich noch komplizierter. Der Grund kann rein trophisch sein, so ziehen zum Beispiel die Zikadenarten bestimmte Nährpfanzen in der oder jener Lage vor. In Hustopeče bei Brno, in sehr warmer Lage wurde in den Jahren 1952-56 auch massenhaftes Auftreten von klassischem Stolbur beobachtet, z. B. auch das Welken der Kartoffeln. Sehr häufig fanden sich hier an Cirsium arvense Scop. die Kennzeichen des sog. europäischen aster yellows. Im Jahre 1957 fanden sich hier Symptome der Virose an A. a. nur stellenweise häufiger. Im Jahre 1958 gab es hier Ende August nur sehr wenig kranke Exemplare von Cirsium arvense L., an Kartoffeln und anderen Pflanzen im Jahre 1958 jedoch keine Symptome klassischen Stolburs. Unter vielen Hunderten von Exemplaren von $A$. a. wurde nur eine einzige Pflanze mit sehr leichten Anzeichen einer Virose gefunden. Im Jahre 1958 konnte es nur zu einer kleinen Zahl von Infektionen infolge des Charakters des Wetters und des so verursachten schwachen und verspäteten Auftretens von Zikaden kommen. Dennoch bleibt die kleine Zahl erkrankter $A$. a.-Exemplare in dieser Lage bisher unerklärlich. Dabei schliessen wir die Möglichkeit einer selektiven Fähigkeit bestimmter Zikadenarten nicht aus, nur manche Viren, oder VirenStämme zu übertragen (BLATTNÝ 1958c).

Herde für Stolbur und andere Krankheiten dieser Gruppe können aller- 
dings auch andere sein, als die, welche wir bisher kennen gelernt haben. Bei uns - in Hustopeče, Loděnice und anderswo - wie auch im Auslande (Nyon in der Schweiz) fanden wir den Vogelknöterich (Polygonum aviculare L.) mit gelblichen bis rosig angehauchten und verkleinerten Gipfelblättern und einer verringerten Blütenzahl, oder überhaupt nicht blühend oder keine Samen erzeugend. Solcher Art erkrankte Pflanzen fanden sich in der Nähe von Ackerwinden und anderen Pflanzen, die von Stolbur oder verwandten Erkrankungen befallen waren. Kvíčala (1958) machte als Erster darauf aufmerksam, dass es sich bei dieser Pflanze um eine Erkrankung durch das Stolbur-Virus oder ein mit ihm verwandtes Virus handeln könnte. Ähnlich kann das auch beim Breitwegerich (Plantago major L.) sein. In Lagen, in denen bei uns die Virose der $A$. $a$. stark auftritt, fanden wir bei dieser Pflanze Phyllodie der unteren Blüten in der Blütenähre, mässig gewellte Blätter mit hervortretenden Adern auf der Unterseite und manchmal anthokyanisiert. Unsere Versuche weisen auf die Übertragbarkeit dieser Virose auf Kartoffeln und auch $A$. a. hin. (Blattiný 1959). In Norditalien fand Grancini (1957) in Lagen, in denen er bei verschiedenen Pflanzen ein reiches Auftreten der europäischen aster-yellows konstatierte, auch sehr häufig hexenbesenförmigen Wuchs bei Plantago major L. und Virescenz der Blüten bei Plantago lanceolata L. In Nyon in der Schweiz (Changins) tritt der klassische Stolbur selten bei Tomaten auf (Bovey 1956). Bei meinem Besuch dortselbst im Jahre 1957 sah ich, dass es dort nirgends ein stolburkrankes Exemplar von Convolvulus arvensis gab. Nirgends habe ich $A$. a. gefunden, weder gesund noch krank. Sehr häufig und schwer erkrankt an Phyllodie fand sich dort nur Plantago major L. vor. Man kann dafürhalten, dass diese Pflanze hauptsächlich als Ansteckungsherd fungierte. Es gibt Lagen, in denen Kartoffeln und Tomaten an typischem klassischem Stolbur erkrankt vorkommen, während $A$. a. grösstenteils an ihrer eigenen, typischen Virose krankt und Lagen, in denen Kartoffeln und Tomaten von klassischem Stolbur befallen sind, während $A$. $a$. grösstenteils gesund geblieben ist und Lagen, in denen bei ähnlich erkrankten Kartoffeln und Tomaten Stellaria media (L.) ViwL. oder Veronica sp., nicht aber $A$. $a$. an Virosen gleichen Typs stark leiden. Analog gilt diese Verschiedenheit auch für Lagen, in denen sowohl Stolbur als auch Ërkrankungen vom Typ der europäischen aster-yellows auftreten. Das gilt auch von Lagen wie es beispielsweise das Vorbergland der Slowakei ist - in denen der klassische Stolbur nicht auftritt, wohl aber ausschliesslich die Erkrankungen vom Typ der europäischen aster-yellows. Wir erachten diese Vorstellungen für die Konsequenzen in einer experimentellen Arbeit schwerwiegend, die vor allem überzeugend feststellen sollte, ob es sich

a) um Virusstämme handelt, die stabilisiert sind oder neu entstehen und unter welchen Bedingungen (z. B. inbezug auf die Temperatur, auf die Wirtsorganismen, ob es sich nun um einen tierischen Vektor oder um einen pflanzlichen Wirtsorganismus handelt);

b) Virusstämme, die lokal, d. i. geographisch stabilisiert oder veränderlich sind;

c) ob es Virusstämme gibt, welche in der oder jener Lage mehr oder minder an bestimmte Wirtsorganismen gebunden sind;

d) ferner, wie die gegenseitigen Beziehungen des Stolbur und seiner Stämme 
sind, des pseudoklassischen Stolbur und der Vergilbungskrankheiten verschiedener Stämme, ihre Koexistenz und Inkompatibilität in Wirtspflanzen und Vektoren;

e) schliesslich, wie die Beziehung der einzelnen Zikadenarten — vor allem trophische - zu verschiedenen Wirtspflanzen ist.

Anagallis arvensis L. resp. Anagallis linifolia L. indizieren die Anwesenheit dieser Virengruppe in einer bestimmten Lage. Es gibt Fälle, in denen es zur Übertragung der Viren nicht anders kommen konnte, als von Kartoffeln (siehe Versuche in Třebotovice und Keřkov). Nicht immer aber indizieren A. a. und Anagallis linifolia L. die Gegenwart dieser Viren in einem bestimmten Kartoffelbestand (siehe beispielsweise Versuch in Mikulov): Auf A. a. könnten diese Kranlkheiten auch von anderen, insbesondere von wildwachsenden Pflanzen anderer Art übertragen worden sein. Bei der grossen Beweglichkeit der Zikaden und auch bei ihren passiven Bewegungen bei Wind kann so etwas verhältnismässig leicht geschehen. Wir kennen Lagen (PrahaBřevnov), in welchen Convolvus arvensis $\mathbf{L}$. an diesen Virosen nicht krankt und nicht einmal kranke Pflanzen von Stellaria media (L.) VuL. zu finden sind, die das Virus über den Winter bewahren könnten. Es handelt sich um abgesperrte Gartenflächen, in die auch ein Zuflug von Zikaden aus anderen, entfernteren Lagen wenig wahrscheinlich ist. In solchen Lagen waren in den Jahren 1956 und 57 diese Virosen an Tomaten häufig: Von 60 Pflanzen des Jahres 1957 waren dort an pseudoklassischem Stolbur 20 Pflanzen (33\%) erkrankt; die Virosen waren weiter häufig an A. a., Stellaria media (L.) VILL., weiter an Zierpflanzen, Callistephus chinensis (L.) Ness, Chrysantheum coronarium L., Scabiosa atropurpurea DESF. und an Allium ampeloprasum L. subsp. porrum (L.) REGEL. Auch im Jahre 1958 trat diese Viruserkrankung auf, jedoch zu sehr kleinem Anteil an $A$. $a$. und an $4 \%$ Tomaten. Wir erklären uns dieses Auftreten durch die Persistenz der Viren in den Zikaden: Calligypona pellucida F. überwintert in ihren Nymphen, bei Macrosteles laevis RiB. ist die Form der Überwinterung noch nicht genügend bekannt (bisher wurde festgestellt, dass diese Art als Ei überwindert). Wir schliessen nicht einmal eine transovariale Übertragung der Viren aus. Und als Überträger kommen vielleicht noch andere, bisher nicht festgestellte Zikadenarten in Betracht.

Unsere Versuche zeigten, dass bei dem Versuche des Jahres 1957 in PrahaDejvice die Virose nicht von $A$. a. auf die Kartoffeln, sondern von den Kartoffel auf $A$. a. überging. Das erwies eigentlich erst der Versuch des Jahres 1958, da auf diesem Felde am 23. 8. 1958 genug Kartoffeln mit Merkmalen von purple-top und yellow-top vorgefunden wurden, die zwischen ihnen wachsenden Pflanzen von $A$. $a$. bei sehr kleiner Zikadenmenge jedoch fast völlig gesund blieben. Wie im Jahre 1957, so gab es auch im Jahre 1958 hier aus den früheren Jahren genug virentragende Zikaden, auch in der Umgebung fanden sich virenbeherbergende Pflanzen vor, _- Stellaria media (L.) VILL., Plantago major L. aber diese Herde reichten offenbar zur Ansteckung nicht aus. Infolge des kühlen und regnerischen Frühjahrs und der ersten Sommerhälfte des Jahres 1958 traten die virophoren Zikaden in weitaus geringerer Zahl und später, als im Jahre 1957 auf. In Mittelböhmen lag ihr Massenauftreten um 14 Tage bis drei Wochen später und war um $9 / 10$ schwächer als im Jahre 1957. In der Umgebung von Prag und an anderen mittel- 
böhmischen und wärmeren Lokalitäten wurden auch die Symptome der Virose bei A. a., mindestens um 14 Tage später, sichtbar, als im Jahre 1957: Im Jahre 1958 Ende Juli, im Jahre 1957 Anfang Juli. Der Anteil an kranken A. a.-Exemplaren des Jahres 1958 sank im Vergleiche zu 1957 bedeutend, an manchen Stellen ganz wesentlich. Es handelte sich also um einen für die Verwendung von $A$. $a$. als Indikatorpflanze für die Gegenwart der Viren der Gruppe der Samenlosigkeit weit ungünstigeren Jahrgang.

Aus diesen Beobachtungen und Versuchen gehen einige Bemerkungen zur Ökologie der Viren hervor:

1. Das Auftreten von Virosen dieser Gruppe schwankt in den einzelnen Jahrgängen insbesondere bei einjährigen Pflanzen stark: Nach einem Jahr des allerstärksten Auftretens kann unter unseren Bedingungen ein Jahr sehr schwachen Auftretens folgen (1957: stark, 1958: sehr schwach).

2. Die Gründe für dieses Schwanken können äussere und innere sein, diese Viren (der Samenlosigkeit-Akarpie, ob es sich nun um Stolburstämme, den pseudoklassischen Stolbur oder die Gruppe aster-yellows handelt) überwintern bei uns in Pflanzen [Convolvulus arvensis L., Stellaria media (L.) VILL., und sicher auch in vielen anderen]. Sie überwintern auch in Zikaden (Calligypona, Hyalesthes). Diese beiden Initialquellen, diese Glieder der Infektionskette sind zwar für die Erhaltung der Art bedeutsam, aber nicht entscheidend für eine Ưbervermehrung in der nächsten, nachfolgenden Periode. Für die Vermehrung des Virus sind weitere Bedingungen entscheidend. Darin stimmt die Übervermehrung der Viren mit den für andere Organismen geltenden Gesetzmässigkeiten überein. Unter die äusseren Bedingungen, die eine Übervermehrung des Virus, sein starkes Auftreten und seine Schädlichkeit bei Pflanzen bewirken, gehört die Menge und Zeitigkeit der Zikadofauna, welche diese Viren überträgt. Eine praktische Applikation dieses Zusammenhangs ist für eine Signalisation sehr bedeutsam.

Am allerunklarsten sind die inneren Bedingungen, wie beispielsweise die Empfindlichkeit verschiedener Pflanzenarten für eine Erkrankung an diesen Virosen. Eine Sammlung der Tatsachen, in der letzten Zeit verbreitet, genügt nicht. Umsoweniger genügt unsere Kenntnis, soweit sie die Empfindlichkeit der Pflanzen in ihren verschiedenen Wachstumsphasen betrifft: die erhöhte Empfindlichkeit der jungen Pflanzen scheint hier keine Allgemeingiltigkeit zu besitzen. Bei diesen Viren ist auch das Schwanken ihres Spiegels in den Pflanzen wichtig und eine Veränderung der Inkubationsdauer im Zusammenhang mit der ontogenetischen Entwicklung der Wirtspflanze (BLATTNÝ 1959).

3. Bedeutsam scheint auch der Einfluss der Wärme und zwar sowohl auf das Virus in den Zikaden, als auch in den Pflanzen zu sein. KUnkel (1937) hat festgestellt, dass das Virus der amerikanischen aster-yellows in den Zikaden praktisch schon bei $32^{\circ} \mathrm{C}$ inaktiviert wird. (Ich lasse Zweifel, die später über diese Beobachtung geäussert worden sind, beiseite.) Im Jahre 1957 erkrankten bei Versuchen in Prag in der Karlovka A. a.-Exemplare, die im Frühjahre aus Samen zwischen Kartoffeln wuchsen, die von purple-top und yellow-top befallen waren, zu 95,1\% an Vergilbung. Die am 10, 7.1957 und danach in den gleichen Bestand gesetzten A. a.-Exemplare, die also nach der Periode des letzten Junidrittels 1957 ausgesetzt waren, als hier die Temperaturen $35^{\circ} \mathrm{C}$ im Schatten erreichten, erkrankten nur zu 6,6\%. Das sehr 
schwache Vorkommen des Stolburs und verwandter Akarpien in Südmähren und der Südslowakei im Jahre 1958 liess sich nicht nur durch die Verspätung und Geringfügigkeit des Vorkommens der Zikaden erklären, sondern auch durch die ausserordentlich warme und trockene Temperaturperiode im Mai und Juni 1958 in Mikulov (am 11. V. $32^{\circ}$ C, am 3. VI. 28, $1^{\circ} \mathrm{C}$ !), welche sich virostatisch äussern konnte. Die steigende Intensität der Erkrankung von $A$. a. und Verwandten an Akarpien im Spätsommer und im zeitigen Herbst spricht von einem günstigen Einfluss niederer (aber nicht zu niedriger) Temperaturen auf die Vermehrung der Viren. Für die gemässigten Ansprüche an den Wärmeverbrach spricht bei Stolbur auch diese bekannte Tatsache: Das starke Auftreten von Stolbur in den kühleren (dabei aber vom mitteleuropäischen Standpunkt aus noch immer warmen) Teilen der Bulgarischen Volksrepublik und das schwache Autreten dieser Virose in ihren sehr warmen Gebieten. Der inaktivierende Wärmepunkt für das Virus des Stolbur und verwandter Erkrankungen liegt nicht allzuhoch. PANJAN (1958) stellte eine günstige thermotherapeutische Wirkung auf das Stolburvirus in Tomatenreisern bei $43^{\circ} \mathrm{C}$ und einer Wirkungsdauer von 24 Stunden fest. Weitere genauere Berichte über Ergebnisse von Versuchen, die in dieser Richtung vorgenommen worden sind, ob es sich nun um eine virostatische Wirkung höherer Temperaturen oder um eine Rehabilitation des Gesundheitszustandes der Pflanzen, in anderem Zusammenhange erworben, handelt, sind in Kürze zu erwarten (Valenta 1958). Schon Engelmann's Feststellung (1832) von einem stärkeren Auftreten pathologischer Blütenformen (von denen wir heute wissen, dass sie infolge von Virosen verändert worden sind) in feuchteren Jahren zeugt vom Einfluss des Milieus, das für die Viren dieser Gruppe über alles wichtig ist.

\section{Literatur}

BLATr'í, C.: Př́spèvky $\mathrm{k}$ poznání virových žloutenek rostlin. I. Květní anomalie drchničky rolní (Anagallis arvensis L.). [Beiträge zur Kenntnis der virösen Vergilbungen der Pflanzen. I. Blütenanomalien bei Anagallis arvensis L.] - Cs. Biologie (Praha) 6:250—265, 1957.

BlatTNý, C.: Klasický a pseudoklasický stolbur u rajěat a bramborů. [Klassischer und pseudoklassischer Stolbur bei Tomaten und Kartoffeln.] _- Preslia 30 : 361 -362, 1958a.

BlatTNÝ, C.: Drchnička rolní, její použiti pro polní test při zjištování stolburoidních onemocnění bramborů. [Ackergauchneil (Anagallis arvensis L.), ihre Verwendung für die Feststellung stolburoider Erkrankungen der Kartoffeln.] — Preslia 30 : 362, $1958 \mathrm{~b}$.

BlatTNÝ, C.: Základní otázky stolburu. Stolbur a príbuzné vírusové bezsemenosti rastlín. [Die Grundfragen des Stolburs. Stolbur und verwandte Virus-Samenlosigkeiten der Pflanzen.] Sborník SAV (Bratislava) $1958: 37-54$, $1958 \mathrm{c}$.

BlatTwý, C.: Modelové studie a pozorování na Anagallis arvensis L. a některých jiných rostlinách. [Modellstudien und Beobachtungen an Anagallis arvensis L. und einigen anderen Pflanzen.] - Ined., 1959.

Blattyý, C., Brð̌á, J., Llmberk, J., BoJñanský, V.: Příspěvek k epidemiologii stolburu v ČR se zvláštním zretelem na brambory. [Beitrag zur Epidemiologie des Stolburs in der Tschechosl. Republik, insbesondere bei der Kartoffel.] - Cs. Biologie (Praha) $5: 95-104$, 1956.

Bovey, R.: Une nouvelle maladie à virus de la tomate en Suisse romande. - Publ. No 514 , Stat. féd. d'essais agricoles, Lausanne, Oct. 1956.

EngelmanN, G.: De antholysi prodromus. - Frankfurt/M. 1832.

Grancini, P.: in lit. 1957. 
Heinze, K., Kunze, L.: Die europäische Asterngelbsucht und ihre Utbertragung durch Zwergzikaden. - Nachrichtenblatt des Deutsch. Pflanzensch. 7 (10): $161-\mathrm{XXX}, 1955$.

KUNKEL, L. O.: Effect of heat on ability of Cicadula sexnotata (Fall) to transmit aster yellows. Amer. J. Bot. $24: 316-327,1937$.

Kvíčata, B.: Mündliche Mitteilung, 1958.

Musit, V., VAl.enta, V.: Prenos stolburu a príbuzných vírusov pomocou niektorých cikád. (Predbežná zpráva). [Die Übertragung des Stolburs mit Hilfe einiger Zwerkzikaden. (Vorläufige Mitteilung).] — Biológia (Bratislava) $13: 133-136,1958$.

Panjan, M.: Stolbur v Juhoslávii. [Stolbur in Jugoslawien.] - Stolbur a príbuzné bezsemenosti rastlín: 102-108, Bratislava 1958.

VAlenta, V.: Mündliche Mitteilung, 1958.

Valenta, V., Musit, M.: Mündliche Mitteilung, 1958.

$\mathrm{WE}_{\mathrm{E}}, \mathrm{R}$. E., Shultz, E. S.: Ladino elover: a possible source of the virus causing purple-top wilt in potatoes. - Plant Dis. Reporter 39:300-301, 1955.

Anschrift des Verfassers: Dr. Ctibor Blattný, Phytopathologische Abteilung des Biologischen Institutes der Tschechoslowakischen Akademie d. Wissenschaften, Karlovka 1, Praha-Dejvice.

\title{
Anagallis arvensis L. как показатель присутствия вирусов из группы акарпий - столбуров и желтух
}

\author{
ЦТИБОР БЛАТТНЫ
}

\section{Резюме}

Желтуха Anagallis arvesis I. свидетельс твует, по напим наблюпениям, о присутствии в природе вируса из группы акарпии (желтух и столбуров). Anagallis arvensis I.., и Stelaria media (I.) VrL. указывают на присутствие в опытах в 1957 г. әтих болезней, и. также purple-top, yellow-top у картофеля в том случаe, если были в наличии Мастоsteles laevis Rib., и Calligypona pellucida F. Oпыт на востекленной террасе при отсутствии обоих впше названных видов показал, что переносчиком приведенных заболеваний не могут быть цикадки Empoasca flavescens, тли различных видов, белокрылка Trialeurodes vaporariorum Westw. В 1958 году, когда численность цикадок была нижс и они появлялись позже, приведенные растения, а также Anagallis linifolia L., указывали на присутствие этих вирусов как на картофельных полях (puple-top, yellow-top даже в предгорьях), так и в других растительных очагах (растениях-резервуарах), или в цикадках, но слабее и позднее чем в 1957 г. Anagallis arvensis L., A. linifolia L. в нејоторых местах точнее свидетельствуют о присутствии aster yellows (европейской желтухи астр) и псевдоклассического столбура, а на других местах группы классического столбура; причины этого явления до сих пор непзвестны. ККелтуха, перенесенная цикадками с. Anagallis arvensis L. на томаты прояв.тялась на них как псевдоклассический столбур. Yellow top картофеля, желтухи и классический столбур, перенесенные цикадками на Anagallis artensis L. проявлялись здесь типичным недоразвитием пепестков. Сильное колебание в распространени и этих вирусов в природе (после 1957 г., когда часто встречались жслтухи в Средней Чехии, пос.тедовал год со слабой заболеваемостью) зависит от начального источника инфекции, от времени, когда начинают появлятся и размножаться цикадки, далее от инактивирующего действия высоких температур, и также от других причин (колебания в численности вирусов в растениях и т. ІІ.).

Растения Anagallis arvensis L., Anagallis linifolia I.. I Stellaria media (L.) VILL. могут служить индикаторами, указывающими на присутствие вирусов из группы акарпий в данном бюотопе. Наблюдсния над составом и фенологией цикадок фауны может служить одним из методов '“игнализации мер борьбы против этих вирусных заболеваний. 